\title{
Nationwide use, challenges, facilitators, and impact of preceptors in prelicensure clinical nursing education
}

\author{
Nancy L. Novotny*1, Debbie Stark ${ }^{2}$ \\ ${ }^{1}$ Mennonite College of Nursing at Illinois State University, United States \\ ${ }^{2}$ Methodist College, Peoria, Illinois, United States
}

Received: December 19, 2019

Accepted: February 23, 2020

Online Published: March 10, 2020

DOI: $10.5430 /$ jnep.v10n6p36

URL: https://doi.org/10.5430/jnep.v10n6p36

\begin{abstract}
Background and objective: Preceptor-facilitated clinical nursing education prevalence information is dated. Information is most often limited to regional baccalaureate programs and provides sparse evidence of its education-related outcomes. The purpose of this study is to describe the nationwide use, structures, facilitators, and challenges of using preceptors in prelicensure clinical education; compare its use by program characteristics; and explore its impact on education-related outcomes.

Methods: In this cross-sectional comparative study, prelicensure programs in randomly selected jurisdictions in all four regions of the US were identified and official pass rates obtained. Program administrators completed an online questionnaire about preceptor use, incentives used, challenges, facilitators, and perceived impact on program capacity.

Results: Preceptors were used in $73 \%$ of the 366 responding programs. Prevalence rates ranged from $25 \%$ to $87 \%$ by program type and from $64 \%$ to $86 \%$ by region. Programs' NCLEX-RN ${ }^{\circledR}$ pass rates and perceived impact on program capacity did not differ by use of preceptors. Most respondents indicated there was no impact although one-fifth perceived moderate to high impact. The top five challenges and facilitators to preceptor use were identified. Programs used a variety of preceptor incentives, ranging from $62 \%$ using informal recognition to $7 \%$ providing some type of financial compensation.

Conclusions: Most programs use preceptors with differences by program type and region. Designating resources to enhance preceptor orientation and preceptor-student-faculty communications may be useful, as well as identifying the challenges and facilitators. While a variety of preceptor incentives are available, few offer direct monetary compensation. Regional preceptor incentive data provide useful benchmarks. With high rates of use in some sectors and yet no demonstrable influence on pass rates, closer scrutiny of the quality of preceptor-facilitated educational experiences and associated outcomes are warranted.
\end{abstract}

Key Words: Preceptors, Prelicensure nursing, Clinical nursing education, NCLEX-RN ${ }^{\circledR}$ pass rates

\section{INTRODUCTION}

The character of prelicensure clinical nursing education has remained relatively consistent for several decades. Involvement of preceptors in the undergraduate's clinical experiences has been part of clinical education in some programs during this time. Despite the lack of a comprehensive study of its use across the United States, generalizations about increased use of preceptor-facilitated clinical education in prelicensure nursing programs are common in literature..$^{[1,2]}$ Within professional nursing education, preceptors are expected to assist in the student's education, socialization, and development of a safe and competent nursing practice as nursing faculty provide direction, supervision, and evaluate student progress. Given sparse objective evidence supporting the effectiveness of this model of prelicensure clinical education, it is important to gain a better understanding of

*Correspondence: Nancy L. Novotny; Email: nlnovot@ilstu.edu; Address: Mennonite College of Nursing at Illinois State University, United States. 
current use of preceptors.

The purpose of this study is to describe the nationwide use, structure, facilitators, and challenges of using preceptors in clinical education; compare its use by program characteristics; and explore its impact on educational outcomes. Evidence from this study is valuable to nursing faculty and administrators in designing the most effective clinical experiences in prelicensure programs.

\subsection{Background}

\subsubsection{Use of clinical preceptors}

Nationwide data about the prevalence of use of preceptors in prelicensure clinicals over the past few decades have not been well-explained and current data are not available. In 1993 Rosenlieb $^{[3]}$ reported that $61 \%$ of 131 NLN-approved RN ${ }^{\circledR}$ programs offered preceptorships. Three years later Oermann $(1996)^{[4]}$ reported preceptor use in clinical teaching in $74 \%$ of 84 NLN-accredited baccalaureate programs in the Midwest. In Altmann administered a survey that was also limited to only baccalaureate programs and these were located in two regions of the US (Altmann, personal communication, August 18, 2014). Altmann reported that $86 \%$ of 226 respondents used preceptors in "some clinical experiences" (2006, p. 9). ${ }^{[5]}$ Timing of the preceptor experiences were described by Oermann but not detailed in Altmann's report. Reported differences across time may have captured actual changes or may be due to differences in target populations or ill-defined definitions.

Two years later a nationwide stratified random sample of 601 new RN's respondents to the NCSBN Spring 2002 Practice and Professional Issues Survey provided an indirect measure of preceptor prevalence: only 35\% reported having an internship/externship, preceptorship, or mentorship experience prior to graduation. ${ }^{[6]}$ This information indicated that the prevalence of preceptors may be lower across the entire US than indicated by earlier studies which sampled select types of programs in limited regions of the US. Reliance upon NCSBN's 2012 definition of preceptor as "an individual, at or above the level of licensure that an assigned student is seeking, who may serve as a teacher, mentor, role model, or supervisor in a clinical setting" (p. 1) would be useful in studies examining the use of this this type of clinical education in prelicensure programs. Researchers continue to refer to dated prevalence rates of preceptors in undergraduate clinical education $^{[7]}$ or describe preceptor use as being widespread without citing quantifiable metrics. ${ }^{[8]}$

\subsubsection{Facilitators and challenges using preceptors}

Factors that facilitate effective use of preceptors in the United States have also not been well documented. The only study identified which concerned this topic focused on ensuring support for preceptors for staff nurses. Carlson and colleagues (2010) ${ }^{[9]}$ identified the usefulness of allocating time for staff nurses to be involved in precepting activities.

Multiple challenges to use of preceptors with prelicensure students, however, have been identified. Many students experience suboptimal clinical experiences due to the staff nurse's inadequate preceptor training or workload. ${ }^{[10]}$ Preceptors also report difficulties with these aspects as well as role ambiguity and conflict ${ }^{[11,12]}$ and inadequate communication with faculty. In some clinical settings preceptors may feel especially powerless or students may be encouraged to engage more in activities to ease staff burden when preceptors face conflicting demands on time ${ }^{[13]}$ than in activities that facilitate student learning. While descriptions of challenges preceptors face in Canada and England are available, ${ }^{[14,15]}$ findings derived from studies conducted where different health and educational systems exist or the preceptorship clinical model of clinical education is used extensively or required may not apply to programs in the US. Challenges involved in preceptor-facilitated clinical instruction and factors which contribute to its effectiveness in the US need further exploration.

\subsubsection{Incentives and compensation for preceptors}

A commonly held belief that nursing professionals are obliged to give back to the profession is cited by some nurses as a reason to be a preceptor. Generational differences seen in nurses' values associated with commitment and compensation $^{[16]}$ with emphasis upon a work-life balance may contribute to a change in this mindset. Willingness of clinical facility nurses to precept students may require incentives beyond intrinsic motivation or non-monetary rewards.

Across non-nursing disciplines monetary compensation for precepting is being more frequently documented, ${ }^{[17,18]}$ with variation noted between geographical regions. ${ }^{[17]}$ Stipends have helped educational institutions retain clinicians' engagement with students and is thought to increase recruitment and retention of high quality preceptors. ${ }^{[17,19]}$

Over 20 years ago Oermann (1996) ${ }^{[4]}$ described a variety of incentives that programs provided to preceptors in bachelor of nursing programs in the Midwest, including recognition, invitations to nursing program functions, or library privileges. At that time Oermann found that approximately 5\% offered financial compensation and over $4 \%$ offered tuition assistance. In 1995 Dibert and Goldenberg ${ }^{[20]}$ pointed out that the lack monetary incentives increased the importance of other benefits or rewards to support preceptors' contributions. This proposed study will identify the use of incentives and monetary compensation provided to undergraduate nursing 
preceptors across all geographical areas in the United States.

\subsubsection{Preceptor influence on program capacity and educa- tional outcomes}

Clinical preceptors may influence students' educational experiences and outcomes. During 2005 as decreased availability of clinical sites was becoming more problematic for nursing programs which hampered expansion of programs, some boards of nursing were concerned with their expectations of increased clinical agency nurse involvement as prelicensure preceptors. ${ }^{[21]}$ Capacity issues in clinical nursing education continues to hamper the expansion of some nursing programs and prompt closer examination of use of preceptors. ${ }^{[22]}$

Preceptor involvement in clinical education may have negative or positive influences upon prelicensure program capacity. During 2013, incorporation of preceptorships to address the lack of clinical sites was at least one strategy in place in $59 \%$ of BSN programs and $41 \%$ of ADN programs in California. ${ }^{[21]}$ At the same time, $46 \%$ of the programs in California faced unavailable clinical placements due to "staff nurse overload or insufficient qualified staff" and 19\% due to nurse residency programs in which staff nurses function as preceptors for newly licensed nurses. ${ }^{[23]}$ Two persistent preceptor-related problems - identification of sufficient qualified preceptors and preceptor stress with workloads which are often not reduced despite additional preceptor role responsibilities - influence clinical placement, nursing program capacity, and effectiveness of preceptor facilitated clinical nursing education.

Nursing literature includes low level evidence about the effectiveness of preceptor involvement in clinical education on students' preparedness for authentic nursing practice and successful transition into the professional nursing role. Development of critical thinking and decision-making skills as well as high NCLEX-RN ${ }^{\circledR}$ pass rates are three desirable outcomes in prelicensure nursing programs. In 2008, however, Udlis concluded that there was little evidence supporting the value of preceptors in clinical education on these outcomes. Although research supports the idea that preceptor models support a positive learning environment, ${ }^{[24]}$ the impact of preceptorships on program capacities and key educational outcomes still need to be quantified.

The outcomes and impact of involving preceptors in undergraduate clinical nursing education remains unknown. This study will compare use of preceptors between regions and types of programs and explore the associations with program outcomes. Information about the prevalence of this model of clinical instruction will help inform educational institutions and clinical agencies about capacity, needed resources, and financial implications. A comprehensive description of the uses, outcomes, and perceived challenges and facilitators of preceptorships across the United States is warranted.

\subsection{Research questions}

A comprehensive study of use of preceptors in prelicensure nursing programs in the United States will address gaps in the literature by answering these questions:

1) What are the prevalence, uses, and reasons for using or not using preceptors in US prelicensure nursing programs?

2) What factors are perceived to facilitate or challenge the use of preceptors?

3) Are there differences in use of preceptors by program characteristics (type, geographical region, and program size)?

4) Is there a difference between use of incentives for preceptors between program types and regions?

5) Are there differences in first time NCLEX-RN ${ }^{\circledR}$ pass rates between use and no use of preceptors?

6) To what extent is use of preceptors perceived to impact program capacity?

\section{METHODS}

\subsection{Design and sampling}

In this cross-sectional, descriptive comparative study, a stratified random sampling process was used to select boardapproved pre-license programs in all four United States Census regions. Jurisdictions, defined as the 50 states and the District of Columbia, were stratified by population density within each region to obtain representative sample of programs in diverse settings. One jurisdiction was randomly selected per stratum. The number of strata within each region was set to include approximately $40 \%$ of the jurisdictions in each region.

A total of 21 sampled jurisdictions included seven in the South, five each in the West and Midwest, and four in the Northeast. All prelicensure nursing programs approved by the respective board of nursing within each jurisdiction were identified. The programs within the randomly selected jurisdictions accounted for approximately $40 \%$ to $60 \%$ of the prelicensure programs within each region. The program administrator's name and workable email address was publicly available for $93 \%$ (878/948) of the programs, ranging from $97 \%$ in the Northeast to $87 \%$ in the West.

In calculations to determine an adequate sample size, a $40 \%$ response rate was anticipated. A sample of at least 328 programs would be sufficient to estimate a prevalence of $\geq 50 \%$ with a $95 \%$ confidence level and precision of $\pm 5 \%$. Additionally, a minimum of at least 99 programs in each preceptor use subgroup would be necessary to identify a four point dif- 
ference from the $82 \%$ average NCLEX-RN ${ }^{\mathrm{R}}$ pass rate for all first time candidates in $2014^{[25]}$ with estimated standard deviation (SD) of 10 , alpha of 0.05 , and power of 0.8 .

\subsection{Data collection}

Data were derived from two sources. Documents publicly available via links on board of nursing websites were used to identify approved prelicensure registered nursing programs in each jurisdiction, program contacts, and to abstract program type and NCLEX-RN ${ }^{\circledR}$ first-time pass rates for 2013 and 2014. If pass rates were not available for these years, rates for 2015 were used if available. The number of candidates each year was also recorded as a proxy for program size. NCLEX-RN ${ }^{\circledR}$ data were not available for three jurisdictions, two in the Northeast and one in the Midwest, and candidate data were not available for two jurisdictions, one in South and one in Midwest. When the program type was not identified in board of nursing documents, data were obtained from program websites.

An online questionnaire was distributed to nursing administrators responsible for oversight of clinical experiences in the program. The questionnaire was designed to elicit information about whether clinical preceptor use was a formal part of the program, reasons for use or non-use, and perceptions about its use on program capacity. Preceptor use was defined as student experience in a clinical setting with faculty oversight that involves clinical agency nurse(s) as a teacher, mentor, role model, or supervisor. Items about reasons for its use and incentives or compensation for the preceptor included defined response options derived from the literature and respondents were provided the opportunity to provide narrative responses. Perceived impact upon program capacity was captured by response options including none, minimal, moderate, or very much. Administrators of programs who used preceptors were also queried about how preceptors are used and the challenges and facilitators associated with use of preceptors. Preceptor use in the program was defined by timing during the final or prior semesters and whether its use was in a required or elective clinical.

The study was approved by the investigators' institutional review boards. Data collection occurred over a year, ending in 2016. Contact with each program's nursing administrator was made via email. Requests to complete the questionnaire were emailed three times, with approximately two weeks between deployments. The authors discovered the third deployment for two jurisdictions in the Southern and Western regions had been unsuccessful after the survey platform was no longer available for their use. Submission of the survey indicated a participant's consent.

Published by Sciedu Press

\subsection{Data analysis}

Descriptive analyses were performed for normally distributed interval variables using means with standard deviations, for non-normally distributed interval variables using the median and range, and for nominal or ordinal data using frequencies with percentages. Median ranked values were reported for the five greatest challenges associated with use of preceptors and most important facilitators for effective preceptor involvement. Each program's NCLEX-RN ${ }^{\circledR}$ pass rate was calculated averaging data from 2013 and 2014 or only the most recent year if both were not available. The number of NCLEX-RN ${ }^{\circledR}$ annual program candidates, used as a proxy for program size, was calculated in the same way.

Comparisons between programs that did and did not use preceptors were made on pass rates, program type, geographic region, and program size. Independent $t$-tests were performed to identify differences in pass rates, and Mann Whitney U for program size; chi square or Fisher's exact was used to identify subgroup associations with program type and geographic region. The median test was used to test for differences across the ordinal rating of perceived extent of impact of clinical preceptors on program capacity. Chi square tests were used to examine differences in perceived impact upon program capacity and preceptor incentives by region and type of program. The $p$ values are reported. Open ended responses were examined for clarifications and to identify common themes concerning use or non-use of clinical preceptors.

\section{RESUlts}

\subsection{Responding programs and characteristics}

The overall response rate was $42 \%$ (366/878) of programs. Programs that did and did not respond were examined for differences in NCLEX-RN ${ }^{\circledR}$ pass rates and program type, region, and size. The mean .01 point difference between pass rates in responders $(\bar{x}=83.59, \mathrm{SD}=10.7)$ and nonresponders $(\bar{x}=83.60, \mathrm{SD}=12.0)$ was not different $(t=.013$, $\mathrm{df}=794, p=.990)$. Response rates by program types were similar (Fisher's Exact $=3.829, p=.279$ ), ranging from $46 \%$ of baccalaureate, $40 \%$ of associate degree, $40 \%$ of diploma, and $33 \%$ of master's entry level. There were differences in regional response rates (Chi square $=33.905, \mathrm{df}=3, p<$ $.001)$. Programs in the Midwest had the highest response rate of $58 \%$, followed by $39 \%$ of West, $37 \%$ of Northeast, and $34 \%$ of South. There were also differences in study participation (Mann Whitney $\mathrm{U}=63652, p=.005$ ) by program size between responding (mean rank $=314$ ) and nonresponding programs (mean rank $=460)$.

All items were complete in 93\% (342/366) of the returned questionnaires. Missing data are identified in results reported. 
In a few instances the administrative contact forwarded the survey to another individual to complete the survey. Respondents identified their institutional title as director or assistant director $(38 \%)$, dean or assistant dean $(38 \%)$, chair or department head $(15 \%)$, coordinator or manager $(4 \%)$, academic officer above dean $(2 \%)$, or faculty $(2 \%)$. Ninety-five percent of respondents identified themselves as directly responsible for key aspects of undergraduate clinical education: $90 \%$ clinical structure, $88 \%$ site selection, $79 \%$ clinical schedules, and $68 \%$ clinical faculty assignments. Fifty-seven percent $(209 / 365)$ were responsible for all four aspects, $25 \%(92 / 365)$ for three aspects, and 13\% (45/365) for at least one. Most of the remaining $5 \%$ mentioned that they maintained indirect oversight for these activities.

Figure 1 depicts the proportional contributions in the sample by program type. Slightly over half of the responding programs were associate degree, followed by bachelor, master's entry level, and then diploma programs. Most programs in the sample were located in the Midwest (36\%) and the fewest in the Northeast $(16 \%)$. The median program size was 63 , with a range of 1 to 963 .

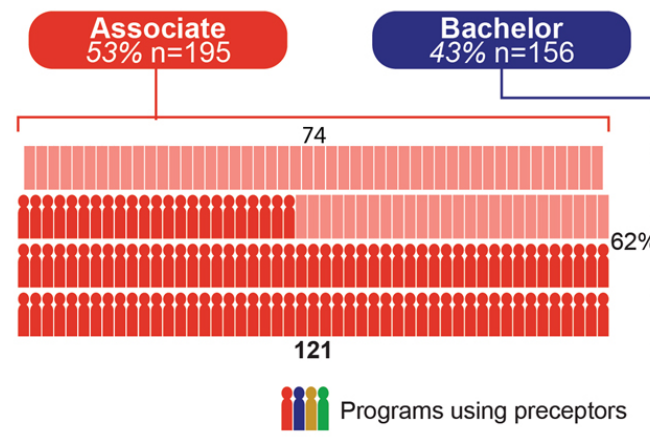

Figure 1. Managers' and nurses' competence assessments

\subsection{Preceptor prevalence and use}

Clinical preceptors were used in 73\% (266/366) of the programs. One program first incorporated preceptors in clinical education in 1940. Fifty-one percent of the programs initiated their use after 2000 and $22 \%$ began use in 2010 or later. Figure 2 summarizes the timing of preceptor use throughout a program and its designation as a required or elective clinical course. In 93\% (248/266) of programs that use preceptors, students have a required preceptor-facilitated clinical during their last semester.

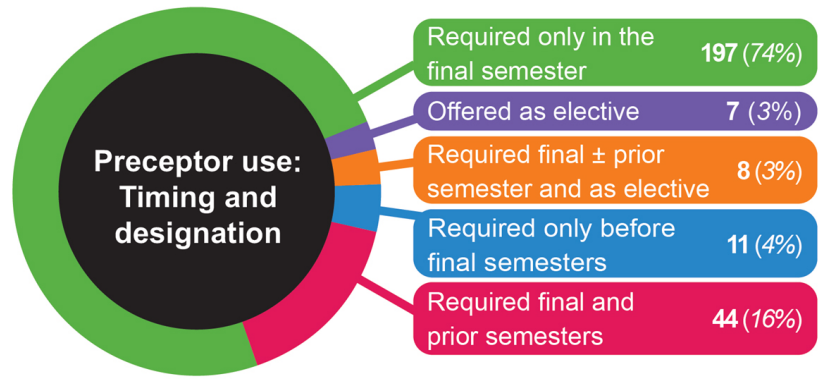

Figure 2. Managers' and nurses' competence assessments

Differences in use of preceptors were examined by program characteristics. As shown in Figures 1 and 3, prevalence differed by program type (Fisher's exact test $=33.297, p<$ .001 ) and by region (Chi square $=11.758$, df $=3, p=.008$ ). Preceptors were more prevalent in bachelor programs and programs in the West; prevalence was lowest in diploma programs and programs in the Northeast. The difference in the size of programs that used (mean rank $=160$ ) and did not use preceptors (mean rank $=149$ ) was not notable (Mann Whitney $\mathrm{U}=8836, p=.339$ ).
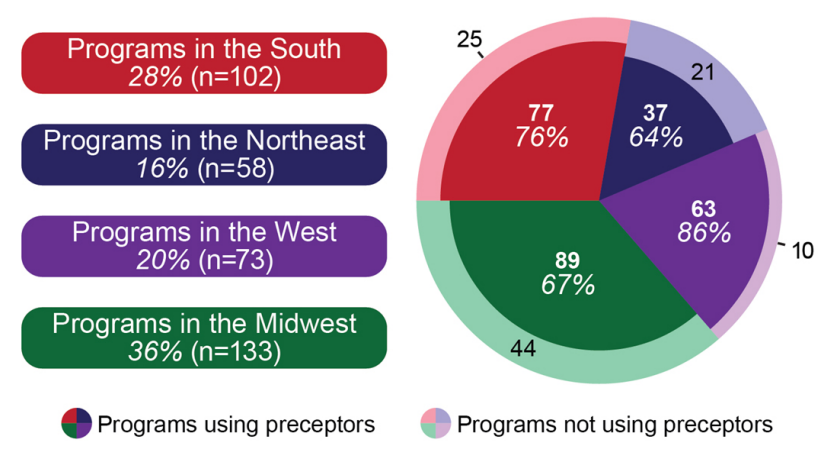

Figure 3. Managers' and nurses' competence assessments

Of the programs not using preceptors, 98\% (98/100) selected all reasons that contributed to not implementing use of preceptors in clinical education; these are summarized in Table 1. The most frequently cited reason for not using preceptors was an insufficient number of available preceptors. In general, reasons for not using preceptors relate to practical/logistical or teaching/learning aspects of clinical education that involve use of preceptors. The reasons are further categorized as fit- 
ting within at least one of three domains: insufficient support or resources for preceptor-facilitated clinical education, lack of perceived need for preceptors, and the use of preceptors would not address current needs.

Additional reasons described in narrative responses included: difficulties due to accreditation requirements, inability to provide preceptor incentives, the work required to implement use of clinical preceptors, and unsatisfactory prior experiences using preceptors in the program. Challenges in maintaining a consistent, equitable, and high quality clinical experience and interactions with poorly qualified preceptors influenced some programs to discontinue preceptor use.

Of the programs that used preceptors, 94\% (249/266) ranked the five most important reasons for using preceptors. The descending order of frequency of reasons identified was mostly consistent with the median ranks. Reasons for use of preceptors, listed in Table 2, also fit into one or more of the same domains used to categorize reasons for not using preceptors. The three reasons identified by over three-fourths of respondents relate to meeting clinical objectives and preparing the student for authentic nursing practice.

Table 1. Reasons for not using preceptors $(n=98)$

\begin{tabular}{|c|c|c|c|c|}
\hline Reasons & n (\%) & $\begin{array}{l}\text { Lacks } \\
\text { support/resources }\end{array}$ & $\begin{array}{l}\text { Lacks } \\
\text { perceived need }\end{array}$ & $\begin{array}{l}\text { Doesn't address } \\
\text { needs }\end{array}$ \\
\hline Do not have sufficient preceptors & $36(36.7)$ & $\mathrm{X}$ & & \\
\hline Already effectively meet clinical objectives & $35(35.7)$ & & $\mathrm{X}$ & \\
\hline Support by clinical facilities is lacking & $33(33.7)$ & $\mathrm{X}$ & & \\
\hline Logistical difficulties with implementation & $32(32.7)$ & $\mathrm{X}$ & & \\
\hline Board of nursing clinical education standards & $24(24.5)$ & $\mathrm{X}$ & & \\
\hline Does not fit with curriculum & $22(22.4)$ & $\mathrm{X}$ & & $\mathrm{X}$ \\
\hline Facilitation into generalist nursing role is adequate & $18(18.4)$ & & $\mathrm{X}$ & \\
\hline Tradition & $18(18.4)$ & & $\mathrm{X}$ & \\
\hline Support of this model by faculty is lacking & $15(15.3)$ & $\mathrm{X}$ & & \\
\hline Faculty shortage not an issue or wouldn't address it & $11(11.2)$ & & $\mathrm{X}$ & $\mathrm{X}$ \\
\hline Student satisfaction & $5(5.1)$ & & $\mathrm{X}$ & $\mathrm{X}$ \\
\hline Students are sufficiently confident in skills & $4(4.1)$ & & $X$ & \\
\hline
\end{tabular}

Table 2. Reasons for using preceptors $(n=249)$

\begin{tabular}{|c|c|c|c|c|c|}
\hline Reasons & n (\%) & $\begin{array}{l}\text { Median } \\
\text { rank }\end{array}$ & $\begin{array}{l}\text { Support/ } \\
\text { resources }\end{array}$ & $\begin{array}{l}\text { Perceived } \\
\text { need }\end{array}$ & $\begin{array}{l}\text { Addresses } \\
\text { needs }\end{array}$ \\
\hline Effectiveness in meeting clinical objectives & $208(83.5)$ & 4 & & & $\mathrm{X}$ \\
\hline Facilitate transition into generalist nursing role & 205 (82.3) & 5 & & $\mathrm{X}$ & $\mathrm{X}$ \\
\hline Increase student confidence in skills & $196(78.8)$ & 3 & & $\mathrm{X}$ & \\
\hline Student satisfaction & $135(54.2)$ & 2 & & $\mathrm{X}$ & \\
\hline Fit with the curriculum & $118(47.4)$ & 3 & $\mathrm{X}$ & & $\mathrm{X}$ \\
\hline Support of this model by nursing program faculty & $117(47.0)$ & 2 & $\mathrm{X}$ & & \\
\hline Support of this model by clinical facility & 79 (31.7) & 2 & $\mathrm{X}$ & & \\
\hline Board of nursing clinical education standards & $53(21.3)$ & 3 & $\mathrm{X}$ & & \\
\hline Help to address faculty shortage & $31(12.4)$ & 2 & $\mathrm{X}$ & $\mathrm{X}$ & $\mathrm{X}$ \\
\hline Tradition & $30(12.0)$ & 1 & $\mathrm{X}$ & $\mathrm{X}$ & $\mathrm{X}$ \\
\hline Reduction in time needed to orient new $\mathrm{RN}$ & $29(11.6)$ & 1 & & $\mathrm{X}$ & $\mathrm{X}$ \\
\hline
\end{tabular}

\subsection{Challenges and facilitators}

Of respondents in programs that used preceptors, $94 \%$ (249/266) identified and ranked the five greatest challenges (barriers or limitations) encountered with use of preceptors

Published by Sciedu Press in their program and five most important factors that facilitate effective use of clinical preceptors. Table 3 summarizes which factors were most frequently identified and their median ranks. Overall factors frequently identified were also 
those which were ranked the highest. Two factors which were most highly ranked as both a challenge and facilitator included the available preceptor pool and a facility's resources and equipment to facilitate the learning needs of students. Additional facilitators included communication between preceptors, students, and faculty; academic-clinical partnerships; a facility's educational policies that are congruent with learning needs; and board of nursing preceptorrelated regulations.

Table 3. Top challenges and facilitators of programs using preceptors $(n=249)$

\begin{tabular}{|c|c|c|c|c|}
\hline \multirow{2}{*}{ Factor } & \multicolumn{2}{|l|}{ Challenges } & \multicolumn{2}{|c|}{ Facilitators } \\
\hline & n (\%) & Median rank & n (\%) & Median Rank \\
\hline Preceptor pool & 198 (79.5) & 5 & $60(24.1)$ & 4 \\
\hline Preceptor-student match and scheduling & $116(46.6)$ & 3 & $56(22.5$ & 2 \\
\hline Preceptor role: Orientation and ongoing education & $115(46.2)$ & 3 & $65(26.1)$ & 3 \\
\hline Preceptors, students, and faculty communication & $94(37.8)$ & 2 & $126(50.6)$ & 4 \\
\hline Support for preceptor role by clinical facility & $90(36.1)$ & 2 & $84(33.7)$ & 3 \\
\hline Preceptor role: Balancing priorities and workload & 89 (35.7) & 3 & $24(9.6)$ & 2 \\
\hline Academic-Clinical partnerships development & $61(25.0)$ & 3 & $122(49.0)$ & 5 \\
\hline Facility’s resources/equipment to support learning & $59(23.7)$ & 4 & $29(11.7)$ & 4 \\
\hline Facility’s clinical education policies: Fit learning needs & $53(21.3)$ & 3 & $63(25.3)$ & 4 \\
\hline Preceptor role: Facilitates learning to meet objectives & $48(19.3)$ & 3 & $35(14.1)$ & 2 \\
\hline Faculty role: Expertise to guide, support, and evaluate & $40(16.1)$ & 2 & $73(29.3)$ & 3 \\
\hline Evaluations of this clinical educational model & 37 (14.9) & 2 & $32(12.9)$ & 3 \\
\hline Preceptor satisfaction & $33(13.3)$ & 2 & 79 (31.7) & 2 \\
\hline Support for preceptor role by academic institution & $23(9.2)$ & 2 & 49 (19.7) & 2 \\
\hline BON preceptor-related regulations or standards & $22(8.8)$ & 3 & $17(6.8)$ & 4 \\
\hline Student satisfaction & $19(7.6)$ & 2 & $76(30.5)$ & 2 \\
\hline Student role: Orientation to site and clinical & $15(6.0)$ & 2 & $26(10.4)$ & 3 \\
\hline Student role: Active engagement & $11(4.4)$ & 3 & $80(32.1)$ & 3 \\
\hline Support for faculty role & $8(3.2)$ & 2.5 & $19(7.6)$ & 2 \\
\hline Faculty support of this model of clinical education & $6(2.4)$ & 3 & $62(24.9)$ & 3 \\
\hline
\end{tabular}

Table 4. Incentives or compensation available to preceptors $(\mathrm{n}=248)$

\begin{tabular}{ll}
\hline Incentives or compensation for preceptors & n (\%) \\
\hline Informal recognition & $165(66.5)$ \\
Contribution to performance review & $111(44.8)$ \\
Included as a clinical ladder role activity & $103(41.5)$ \\
Formal recognition & $72(29.0)$ \\
Networking & $54(21.8)$ \\
Participation in free or lower cost educational programs & $32(12.9)$ \\
Contribution to merit increase or bonuses & $28(11.3)$ \\
Additional pay for preceptor hours & $17(6.9)$ \\
Reduced workload during preceptor hours & $13(5.2)$ \\
CEU's provided & $10(4.0)$ \\
Stipend & $3(1.2)$ \\
\hline
\end{tabular}

\subsection{Preceptor incentives and monetary compensation}

Of the programs that used preceptors, 93\% (248/266) provided information about incentives or compensation avail- able for preceptors. As outlined in Table 4, the commonly used incentives included informal recognition or other inducement that could contribute toward career development or advancement. In $8 \%(20 / 248)$ of the programs, preceptors were provided direct compensation via additional pay or a stipend. Indirect compensation was also possible for preceptors in $23 \%$ (57/248) programs through either free or reduced fees for educational programs and/or its contribution to merit increase or bonus. Only $7 \%$ of the programs used no incentives.

In response to the item inquiring about the most important reasons to provide preceptors with monetary compensation, $5 \%$ indicated there were no reasons to provide financial remuneration. The majority of respondents thought that financial compensation would help ensure a sufficient number of willing preceptors $(56 \%)$ and ensure a pool of well-qualified preceptors (54\%). Twenty-eight percent believed it was "the 
right thing to do". Lastly, 7\% of programs believed that it was a good reason to compensate preceptors in their program because preceptors in other nursing or other health discipline programs were being compensated locally.

There were no indications that programs differed in incentives or compensation offered to preceptors by program type or size. There were, however, some differences in use of preceptor compensation and incentives by region in several aspects. No Northeastern programs provided a stipend or additional pay for preceptor hours, while $18.3 \%$ of Western, $6.8 \%$ of Southern, and $4.8 \%$ of Midwestern program (Fisher's Exact $=10.810, \mathrm{df}=3, p=.009$ ). Networking incentives were offered by $35 \%$ of programs in the West, $28 \%$ in the Northeast, $19 \%$ in the Midwest, and $11 \%$ in the South (Chi square $=12.236, \mathrm{df}=3, p=.006$ ).

\subsection{Preceptor influence on NCLEX-RN ${ }^{\circledR}$ pass rates and program capacity}

In the sample, the overall mean NCLEX-RN ${ }^{\circledR}$ pass rate was $83.6(\mathrm{SD}=11.5)$. Use of preceptors did not make a difference in NCLEX-RN ${ }^{\circledR}$ pass rates. The mean pass rate of programs that used preceptors was slightly less than one point higher than programs that did not use preceptors $(t=$ $.733, \mathrm{df}=324, p=.46)$. There were also no differences when examined by program sub-types.

Approximately $53 \%$ of all respondents perceived clinical preceptors to have no impact upon program capacity. A total of $27 \%$ perceived minimal impact and $20 \%$ perceived the impact to be moderate or very much. Perceived impact on program capacity was independent of a program's use of preceptors $\left(\chi^{2}=2.13, \mathrm{df}=3, p=.57\right.$ ), program type (Fisher's exact $=7.47, p=.518)$, and region $($ Chi square $=1.305$, $\mathrm{df}=$ $3, p=.728)$. The median program size of programs selecting none $=56$, minimal $=67$, moderate $=69$, and very much $=118$. A trend was identified in that the median program size increased as perceived impact increased (median test $=7.027, \mathrm{df}=3, p=.071)$. The median program size of programs selecting none $=56$, minimal $=67$, moderate $=69$, and very much $=118$.

\section{Discussion}

\subsection{Use of preceptors}

This is the first comprehensive report identifying differences in use of clinical preceptors across program types, program size, and geographic regions throughout the United States. The overall prevalence of preceptor use was $73 \%$, which is close to the rate Oermann reported in 1996 and yet 13\% lower than Altmann's (2006) ${ }^{[5]}$ more recent report. The inclusion of only baccalaureate programs in prior studies and imprecise definitions of preceptors may be factors related to different rates. Our findings that $93 \%$ of clinical preceptor use occurs in the final semester are consistent with Oermann's 1996 report that that $91 \%$ of the preceptors used in the Midwestern baccalaureate programs occurred in the senior year. Information about the extent and timing of preceptors is useful in planning for clinical placement which take into account staff nurses' contributions to various stages of students' prelicensure education. Understanding clinical placement timing may also be useful in evaluating preceptor facilitated clinical experiences on educational outcomes.

\subsection{Facilitators and challenges}

There were notable contrasts and similarities between the most common reasons for using or not using preceptors in prelicensure clinical education. One of the highest rated reasons for using and not using preceptors relates to whether the use helps effectively meet clinical objectives. Several reasons were not identified by many respondents for use or non-use of preceptors. These included tradition and faculty shortage. A fit with the curriculum was identified by almost twice as many programs that use preceptors than programs that did not use preceptors. Further programs using preceptors identified facilitation into generalist nursing role four times more often than programs that did not use preceptors.

This study offers the first report of factors that facilitate effective or efficient use of preceptors in clinical nursing education in prelicensure programs. This study also supports previously identified challenges and identifies additional challenges. Respondents who identified preceptor pool as an important factor tended to rank this high. Of these $24 \%$ identified it as a facilitator and $80 \%$ identified it as a challenge. The next highest ranked challenge was Facility's resources/equipment to support learning, was also highly ranked as a facilitator. The academic-clinical partnership was seen as one of the top two facilitators and was the highest ranked. It was also identified by one-fourth of the respondents as a challenge but only a moderate rank. Communication between preceptors, students, and faculty was identified by the largest percentage of respondents as a facilitator and was also one of the highest ranked.

\subsection{Preceptor incentives and monetary compensation}

Compared to Oermann's (1996) ${ }^{[4]}$ report, a wider variety of preceptor incentives were identified in this study. Likewise, direct and indirect monetary compensation for preceptors increased, although the percentage of programs offering this remains low overall. This study also identified differences in regional preceptor incentives or rewards, which was previously only identified with use of preceptors outside of nursing. ${ }^{[26]}$ The preceptor incentives and compensation data 
provide useful benchmarks for nursing programs that continue to compete for clinical site placements for their students in a changing workplace environment.

A question that has arisen in graduate nursing and other healthcare education ${ }^{[26-28]}$ may also apply to use of preceptors in undergraduate nursing programs. If preceptors are integrally involved in educating students and contribute to effective learning outcomes, isn't it just as appropriate to provide preceptors with monetary compensation as it is to pay nursing program administrators for their contributions? Being a student's preceptor occurs concurrently while fulfilling duties and responsibilities to the preceptor's employer. Future studies that examine the performance of the preceptor role within this context demands stakeholders consider the cost-benefits for all parties involved and the role of academicclinical partnerships in effective implementation of the preceptor role given challenges identified in maintaining an adequate preceptor pool.

\subsection{Preceptor influence on NCLEX-RN ${ }^{\circledR}$ pass rates and program capacity}

Findings in this study did not identify associations between preceptor use and education-related outcomes. First, no difference was found in NCLEX-RN ${ }^{\circledR}$ pass rates. Our further exploration of pass rates by use of preceptors within program types was based on Fusner's (2002) ${ }^{[29]}$ preliminary subgroup analyses which identified higher pass rates in AD programs using preceptors compared to those that did not. Our subgroup analyses, which involved larger samples than Fusner's, did not reveal pass rate differences by preceptor use within any program type. Failure to recognize the influence of preceptor use on pass rates may occur due to variation in implementation of the preceptor-facilitated clinical education model among programs. Because student-preceptor interactions are believed to influence development of critical thinking and decision-making skills, ${ }^{[30]}$ investigation of the finer aspects of the preceptor clinical experiences may be necessary to discern differences in outcomes between various models of clinical education.

One-fifth of the programs perceived that preceptor use had a moderate to high impact upon program capacity, while slightly more than half did not perceive it to have any impact. Differing perspectives about influence on capacity, however, were not based upon a program's use of preceptors, region, or program type. Beyond these findings, further exploration of the preceptor's role on clinical education capacities deserve attention given two issues. First, preceptors can be considered as a factor in a clinical facility's capacity to support the learning needs of a certain number of student nurses. ${ }^{[31]}$ Second, there is a common perception that use of preceptors in prelicensure clinical education helps address faculty shortage and hence improve program capacity.

A trend, however, was noted between an increase in program size and perceptions that preceptor use had an impact on program capacity. Program size may influence how adeptly a program leverages resources available in a preceptor facilitated clinical education model. In this study no comparisons were made based on faculty-to-student ratios, which may influence this issue and help explain the findings. Further, it may be necessary to go beyond quantification of perceived impact upon program capacity by using more objective measures. Drilling down to specific student experiences with preceptors may also help identify differences in educational outcomes.

\subsection{Limitations and strengths}

There were some limitations in this study. The return rate was lower than previous reports of the preceptor prevalence and notably higher for schools in the Midwest compared to other regions. This may be due in part to the electronic distribution and deployments to several jurisdictions only twice. Despite this limitation the resultant sample size was adequate to estimate the prevalence rate with confidence.

The study's strength was enhanced with use of a clear definition of preceptors which was consistent with NCSBN preceptor-related guidelines. This will be important for subsequent studies which examine future trends. Also, the sample provided a credible representation of programs across the nation for NCLEX-RN ${ }^{\circledR}$ pass rates and program types. This also facilitated valuable comparisons across programs and subgroups for future comparisons and benchmarking.

\section{Conclusion}

Overall the use of preceptors in prelicensure clinical nursing education nationwide was $73 \%$. In some sectors the rate of preceptor use in prelicensure clinical nursing education was even higher with variations by program type and geographical region. Rates ranged from $87 \%$ in bachelor programs to $25 \%$ in diploma programs and from $86 \%$ in the West to $64 \%$ in the Northeast. Within programs using preceptors, the nearly universal use in the final prelicensure semester indicates a prevailing emphasis of the need for real-world practice experience for transition into the professional nursing role. The issue that most often influenced both decisions to use and not to use preceptors was effectiveness in meeting clinical objectives, while the most common reason not to use preceptors was the lack of sufficient preceptors. Identification of aspects the influence students' success meeting clinical objectives in both programs that do and don't use preceptors could provide valuable insights for all programs. 
The importance of the pool of preceptors was also highlighted as the programs which used preceptors identified the top five challenges and facilitators. The available pool of preceptors was identified most often and ranked as the highest challenge as well as one of the highest ranked facilitators. Growing nursing school-clinical agency partnerships may be an important step for ongoing development and recruitment of preceptors. Nursing programs evaluating the inclusion of preceptors in their model of clinical education would benefit from review of the lists of challenges and facilitators in their deliberations.

Programs used a variety of preceptor incentives, ranging from $62 \%$ using informal recognition to $7 \%$ providing some type of financial compensation. Regional preceptor incentive and compensation data provide useful benchmarks, especially for programs facing challenges in finding sufficient preceptors to meet their clinical placement needs.

Without any difference identified in first-time NCLEX-RN ${ }^{\circledR}$ pass rates with use of preceptors plus the limited perceived impact of use of preceptors on program capacity identified in this study, it is desirable to closely document well-defined characteristics and evaluate quality-related aspects involved in use of preceptors with a cost/benefit analysis. It would also be valuable to explore factors associated with differences in perceived program capacity to identify how to most efficiently and effectively use a preceptor-facilitated model of clinical education. Lastly and importantly, given that most prelicensure programs are using preceptors and significant educational and programmatic challenges involved in using preceptors, an objective comparison of how well students meet learning objectives and program outcomes is warranted between programs which use and do not use preceptors. Acknowledgements

\section{ACKNOWLEDGeMents}

The authors would like to thank the Xi Pi chapter of Sigma Theta Tau International for support by partial funding of this research and Ryan J Smith, M.F.A., for creating graphs.

\section{CONFLicts OF InTEREST Disclosure}

The authors declare that there is no conflict of interest.

\section{REFERENCES}

[1] L'Ecuyer KM, von der Lancken S, Malloy D, et al. Review of state boards of nursing rules and regulations for nurse preceptors. Journal of Nursing Education. 2018; 57(3): 134-141. PMid:29505070 https://doi.org/10.3928/01484834-20180221-02

[2] Harrison TM, Stewart S, Ball K, et al. Clinical Focus Program: Enhancing the transition of senior nursing students to independent practice. JONA. 2007; 37(6): 311-317. PMid:17563525 https: //doi.org/10.1097/01. NNA.0000277721.64629.6e

[3] Rosenlieb CO. A profile of preceptorships in baccalaureate degree nursing programs for registered nurses. In N. L. Diekelmann and M. L. Rather (Eds.). Transforming RN education: Dialogue and debate. (pp. 256-272). New York: National League for Nursing Press. 1993.

[4] Oermann MH. A study of preceptor roles in clinical teaching. Nursing Connections. 1996; 9: 57-64.

[5] Altmann TK. Preceptor selection, orientation, and evaluation in baccalaureate nursing education. International Journal of Nursing Scholarship. 2006; 3(1): 1-16. PMid:16646936 https://doi .org/10.2 202/1548-923X.1014

[6] Smith JE, Crawford LH. Report of findings from the Practice and Professional Issues Survey, Spring 2002, NCSBN Research Brief. Chicago: National Council of State Boards of Nursing. 2003.

[7] Hall KC. Role functions of staff nurse preceptors for undergraduate prelicensure nursing students. Journal of Nursing Education and Practice. 2016; 6(7): 19-30. https://doi.org/10.5430/jnep.v $6 \mathrm{n} 7 \mathrm{p} 19$

[8] Udlis KA. Preceptorship in undergraduate nursing education: An integrative review. Journal of Nursing Education. 2008; 47: 20-29. PMid:18232611 https://doi.org/10.3928/01484834-20080 101-09

Published by Sciedu Press
[9] Carlson E, Pilhammar E, wann-Hansson C. Time to precept: Supportive and limiting conditions for precepting nurses. Journal of Advanced Nursing. 2010; 66(2): 432-441. PMid:20423426 https : //doi.org/10.1111/j.1365-2648.2009.05174.x

[10] Varley L, MacMamara C, Mannix-McNamara P. Preceptorship: Exploring the experiences of final year student nurses in acute hospital setting. Journal of Hospital Administration. 2012; 1(2): 42-52. https://doi.org/10.5430/jha.v1n2p42

[11] McClure E, Black L. The tole of the clinical preceptor: An integrative literature review. Journal of Nursing Education. 2013; 52(6): 335341. PMid:23621122 https://doi.org/10.3928/01484834-2 0130430-02

[12] Omansky G. Staff nurses' experiences as preceptors and mentors: An integrative review. Journal of Nursing Management. 2010; 18(6): 697703. PMid:20840364 https://doi.org/10.1111/j.1365-283 4.2010.01145.x

[13] Twinn S, Davies S. The supervision of Project 2000 students in the clinical setting: Issues and implications for practitioners. Journal of Clinical Nursing. 1996; 5: 177-183. PMid:8705083 https : //doi.org/10.1111/j.1365-2702.1996.tb00247.x

[14] Sedgwick M, Harris S. A critique of the undergraduate nursing preceptorship model. Nursing Research and Practice. 2012; article 248356. PMid:22649721 https ://doi .org/10.1155/2012/248 356

[15] Tracey JM, McGowan IW. Preceptors views on their role in supporting newly qualified nurses. British Journal of Nursing. 2015; 24(20): 998-1001. PMid:26559102 https://doi.org/10.12968/bjon. 2015.24 .20 .998

[16] Hendricks JM, Cope VC. Generational diversity: What nurse managers need to know. Journal of Advanced Nursing. 2013; 69(3): 717 725. PMid:22775766 https ://doi.org/10.1111/j.1365-264 $8.2012 .06079 . x$ 
[17] Anthony D, Jerpbak CM, Margo KL, et al. Do we pay our community preceptors? Family Medicine. 2014; 46(3): 167-173.

[18] Skrabal MZ, Jones RM, Nemire RE, et al. National survey of volunteer pharmacy preceptors. American Journal of Pharmaceutical Education. 2008; 72(5): Article 112. PMid:19214266 https : //doi.org/10.5688/aj7205112

[19] Peters AS, Schnaidt KN, Zivin K, et al. How important is money as a reward for teaching? Academic Medicine. 2009; 84: 42-46. PMid:19116476 https ://doi .org/10.1097/ACM. 0b013e3181 90109c

[20] Dibert C, Goldenberg D. Preceptors' perceptions of benefits, rewards, supports, and commitment to the preceptor role. Journal of Advanced Nursing. 1995; 21(6): 1144-1151. PMid:7665780 https: //doi.org/10.1046/j.1365-2648.1995.21061144.x

[21] National Council of State Boards of Nursing (NCSBN). (2005). Clinical Instruction in Prelicensure Nursing Programs Position Paper. 2016. Available from: https://www.ncsbn.org/Final_Clinic al_Instr_Pre_Nsg_programs.pdf

[22] American Association of Colleges of Nursing. (2008). Nursing shortage. Available from: http://www. aacn.nche.edu/Media/Fact Sheets/NursingShortage.htm

[23] Waneka R, Bates T, Spetz J. California Board of Registered Nursing 2013-2014 Annual School Report Data Summary for Prelicensure Nursing Programs. San Francisco, CA: California Institute for Nursing \& Health Care. 2015. Available from: http: //www.rn.ca.gov/pdfs/schools/prelicensure13-14.pdf
[24] Franklin N. Clinical supervision in undergraduate nursing students: A review of the literature. E-Journal of Business Education and Scholarship of Teaching. 2013; 7(1): 34-42.

[25] National Council of State Boards of Nursing (NCSBN). (January 21, 2015). 2014 Number of Candidates Taking NCLEX Examination and Percent Passing, by Type of Candidate. Chicago: National Council of State Boards of Nursing. 2016. Available from: https://www.ncsbn.org/Table_of_Pass_Rates_2014.pdf

[26] Anthony D, Jerpbak CM, Margo KL, et al. Do we pay our community preceptors? Family Medicine. 2014; 46(3): 167-173.

[27] Frank BE, Fields SC. Medical education: What are students paying for? Family Medicine. 2014; 46(3): 16-166.

[28] Gardenier D, Arends R, Selway J. Should preceptors be paid? The Journal for Nurse Practitioners. 2019; 542-543. https://doi.or $\mathrm{g} / 10.1016 / \mathrm{j}$. nurpra. 2019.06.007

[29] Fusner SJ. A study of the effect of preceptor programs in prelicensure nursing education on NCLEX-RN ${ }^{\circledR}$ pass rates. Unpublished dissertation. Retrieved from ProQuest (UMI No. 3062152). 2002.

[30] Hendricks S, DeMeester D, Stephenson E, et al. Stakeholder perceptions, learning opportunities, and student outcomes in three clinical learning models. Journal of Nursing Education. 2016; 55(5): 271-277. PMid:27115454 https://doi.org/10.3928/01484834-20160 414-06

[31] Hutchings A, Williamson GR, Humphreys A. Supporting learners in clinical practice: Capacity issues. Journal of Clinical Nursing. 2005; 14(8): 945-955. PMid:16102146 https://doi.org/10.1111/j . $1365-2702.2005 .01239 . x$ 